\title{
MELANIN INHIBITORS AND THE EBONY LOCUS IN DROSOPHILA MELANOGASTER
}

\author{
P. A. PARSONS \\ Department of Genetics, University of Cambridge \\ and \\ R. A. KROMAN * \\ Department of Biology, Long Beach State College, California
}

Received 9.vi.6o

\section{INTRODUCTION}

IT is well known that some mutants in Drosophila, such as ebony $(e)$, have more melanin than the wild-type. In this paper data will be presented on the ability of inbred and mass bred larvæ of ebony, wild-type and heterozygous ebony genotypes to survive on foods containing various concentrations of two melanin inhibitors, phenylthio-carbamide (P.T.G.) and silver nitrate $\left(\mathrm{AgNO}_{3}\right)$. A preliminary discussion has been given by Kroman and Parsons (r96o).

The biochemistry of melanin formation in Drosophila is not precisely known, although many reactions are known relatively well (see review by Lerner and Fitzpatrick, 1950). Phenyl-thio-carbamide is an organic sulphur compound which inhibits melanin production by combining with copper ions necessary for the action of the enzyme tyrosinase. Tyrosinase catalyses the conversion of tyrosine to dopa, which is an early reaction in the sequence leading to melanin formation. When formed, dopa also appears to catalyse this reaction, but the remainder of the reactions leading to melanin formation are probably auto-catalytic. The inhibitory effect of $\mathrm{AgNO}_{3}$, a heavy metal compound, is presumably due to its interaction with the enzyme itself. In the presence of sub-lethal doses of $\mathrm{AgNO}_{3}$, flies are bleached to a yellow-white colour (Rapoport, I947), and are often greatly reduced in size, but in the presence of sub-lethal doses of P.T.C., the flies are phenotypically unchanged except that they are reduced in size.

\section{METHOD}

Various concentrations of P.T.C. and/or $\mathrm{AgNO}_{3}$ were mixed with a standard corn-meal and molasses medium. Larvæ not more than 12 hours old were placed on the medium and the number of adult flies emerging from a given number of larvæ counted for various genotypes.

Mass bred genotypes $e^{11} e^{11}, e^{11}+$, and $++\left(+=\right.$ Oregon stock, $e^{11}=$ ebony $\left.{ }^{11}\right)$ were tested, as well as inbred flies of the same three genotypes. The inbred flies were produced by single pair mating individuals heterozygous for $e^{11}$ for 17 consecutive generations. Hence they ought to be genetically very similar as well as

* Supported, in part, by a Fellowship from the National Cancer Institute of the National Institutes of Health, U.S.A. 
nearly homozygous except in the region of the segregating $e^{11}$ locus. In table I results are presented for various trials. Each entry represents the number of adult flies emerging from 100 larvæ (4 replicates of 25 larvæ).

\section{RESULTS FOR MASS BRED GENOTYPES}

(collected at Department of Genetics, Davis, California)

Considering firstly the mass bred flies on $\mathrm{AgNO}_{3}$ (table $\mathrm{r} a$ ), we see that $0_{1}{ }_{5}$ per cent. $\mathrm{AgNO}_{3}$ reduced the emergence of all genotypes compared with the control. The emergence of ++ flies was reduced most, and $e^{11} e^{11}$ least. A similar trend can be seen for 0.25 per cent. $\mathrm{AgNO}_{3}$. Thus $e^{11} e^{11}$ genotypes can tolerate a higher concentration of $\mathrm{AgNO}_{3}$ than $e^{11}+$, and in turn $e^{11}+$ tolerates a higher concentration than ++ . This is confirmed by the emergence at 0.30 per cent. $\mathrm{AgNO}_{3}$ of only two flies, both $e^{11} e^{11}$. At high concentrations of $\mathrm{AgNO}_{3}$, a white phenocopy of the type reported by Rapoport (I947) was shown. This was most severe for ++ and $e^{11}+$ genotypes which are initially lighter in colour than $e^{11} e^{11}$, and presumably have less melanin. Thus the high concentration of melanin in $e^{11} e^{11}$ flies may give some measure of protection against $\mathrm{AgNO}_{3}$.

P.T.C., on the other hand, was most lethal to $e^{11} e^{11}$ flies. At 0.04 per cent. P.T.C., no $e^{11} e^{11}$ flies emerged, whereas ++ and $e^{11}+$ flies emerged from concentrations as high as 0.12 per cent. P.T.C. Thus, the two inhibitors have opposite effects on viability.

An examination of the data in table $\mathrm{I} b$ for 0.04 per cent. P.T.C. to 0.08 per cent. P.T.C. reveals a general tendency for the total number of flies to decrease; but within this range the decrease is almost entirely due to a decline in the emergence of ++ flies. This observation suggests a possible heterotic effect at high concentrations of P.T.C.; an effect which can be tested statistically.

Let $t$ be the percentage P.T.C. in units of o.o I per cent., and let $a^{\prime}{ }_{i}$ and $a_{i}$ be the observed numbers of ++ and $e^{11}+$ respectively and $n_{i}$ the sum $a_{i}^{\prime}+a_{i}$. Further, let $q=S\left(a_{i}^{\prime}\right) / S\left(n_{i}\right), p=S\left(a_{i}\right) / S\left(n_{i}\right)$ and $S\left(t x a^{\prime}\right)=A^{\prime}, S(t x a)=A$, and

We may then calculate

$$
S(t-\bar{t})^{2}=S\left(t^{2} n\right)-\frac{[S(t n)]^{2}}{S n}
$$

$$
\chi_{1}^{2}=\frac{q A-p A^{\prime}}{p q S(t-\bar{t})^{2}}
$$

which tests the significance of the linear trend that ++ decreases more than $e^{11}+$ with increasing P.T.C. concentration (Holt, 1948). This $\chi^{2}{ }_{1}$ came to $5^{*} 82$ which is significant at $\mathrm{P}=0^{\circ} 02$. A contingency $\chi^{2}{ }_{4}$ can be computed on the $2 \times 5$ table made up of the genotypes ++ and $e^{11}+$, and the 5 concentrations of P.T.C. This came to $7 \cdot 62(0 \cdot 1<\mathrm{P}<0 \cdot 2)$. Subtracting the $\chi_{1}^{2}$ for the linear trend leaves $\chi_{3}^{2}=\mathrm{I} \cdot 80(0.5<\mathrm{P}<0.7)$ for heterogeneity, which is not significant. Hence we have evidence for heterosis becoming more 
marked as the P.T.C. concentration increases. Thus there is a change in dominance according to the P.T.G. concentration. At 0.04 per cent. P.T.G., emergence appears to be correlated with the degree of

TABLE I

Number of adult flies emerging from roo larve for various concentrations of $\mathrm{AgNO}_{3}$ and P.T.C.

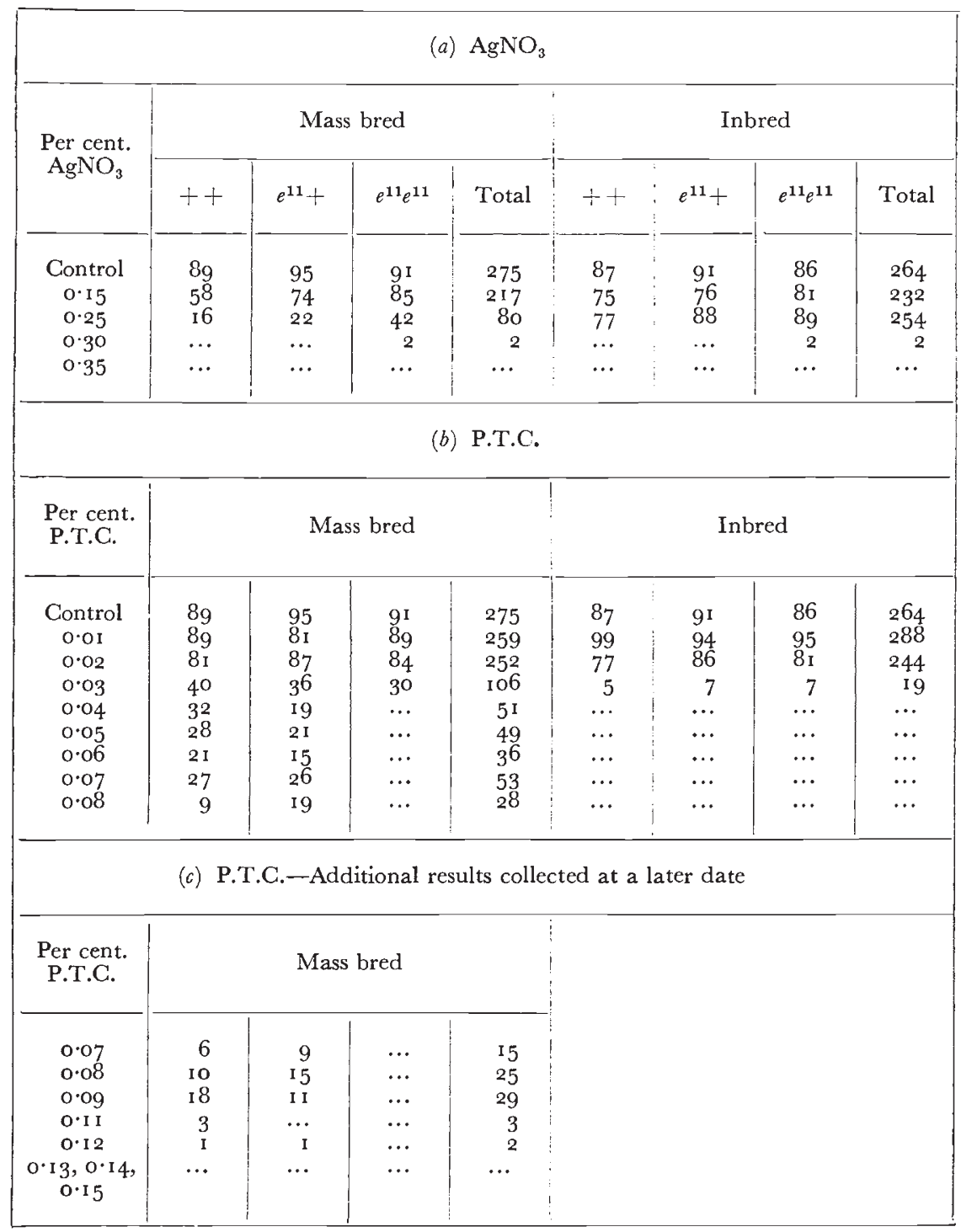

melanisation of the flies, but at 0.08 per cent. P.T.C., there is no such correlation, and another system involving heterosis appears to be demonstrated. 
In table I $c$ are data collected from flies raised at a later date on a different food batch which do not show heterosis. Since the level of P.T.C. in these experiments ranged from 0.07 to 0.15 per cent. this is not surprising. These data also show that inferences, must be made on results collected from the same batch of food, to be valid.

\section{IṆBRED FLIES}

On 0.25 per cent. $\mathrm{AgNO}_{3}$, more inbred flies survived than mass bred flies. This increase in survival compared with the mass bred flies is probably due to the inbreeding system used, which was the single pair mating of individuals heterozygous for $e^{11}$ in each generation. As $e^{11}+$ is not much darker than ++ , it may be supposed that there would be a tendency for the darkest $e^{11}+$ flies to be selected to be sure that they were $e^{11}+$. Such selection did in fact take place as the ++ and $e^{11}+$ genotypes extracted at the 17 th generation of inbreeding were visibly darker than the corresponding mass bred genotypes. In the mass bred flies, there was a correlation between melanin content and ability to emerge, and this relation occurs in the inbred flies if it is assumed that selection has favoured more extreme melanisation. Hence there is a substantial background of modifiers on which selection has acted.

Since selection for increased melanisation has occurred, we would expect fewer flies to survive on P.T.G., which was most toxic to the $e^{11} e^{11}$ mass bred flies. Table I shows that few flies emerged at 0.03 per cent. P.T.C. and none at 0.04 per cent. P.T.G. There was no significant advantage of the $e^{11}+$ and ++ genotypes over $e^{11} e^{11}$ as occurred in the mass bred stocks. Presumably this is because the melanin content of the ++ and $e^{11}+$ genotypes has been increased sufficiently for the lethal dose of P.T.C. to become almost equivalent for all genotypes. Similarly, the inbred flies on $\mathrm{AgNO}_{3}$ did not show such a marked gradation from ++ to $e^{11} e^{11}$ as the mass bred flies.

These results therefore show that the two chemicals $\mathrm{AgNO}_{3}$ and P.T.C. inhibit development at some stage, and that the inhibition is related to the degree of melanisation of the flies, which in turn is controlled by a major gene and a background of modifiers on which selection acted.

\section{P.T.C. AND $\mathrm{AgNO}_{3}$ MIXED IN THE MEDIUM}

Since $\mathrm{AgNO}_{3}$ was most lethal to ++ , and P.T.G. to $e^{11} e^{11}$, it might be expected that mixtures of the two chemicals in the medium would favour the survival of heterozygotes at higher concentrations than the homozygotes. In table 2 the results of several such tests are given.

Emergence on 0.30 per cent. $\mathrm{AgNO}_{3}$ was higher than on 0.20 or 0.25 per cent. $\mathrm{AgNO}_{3}$. As the cultures with o.3o per cent. $\mathrm{AgNO}_{3}$ were made up later than those with the lower concentrations of $\mathrm{AgNO}_{3}$, 
it is likely that some slight change in the procedure used in making up the medium, such as the temperature to which it was heated, or the length of time it was cooked, might account for the difference. Perhaps the temperature at which P.T.C. and $\mathrm{AgNO}_{3}$ are added may be important. On mixing solutions of P.T.C. and $\mathrm{AgNO}_{3}$ an insoluble black precipitate is formed. This reaction may not proceed to completion in the medium. For levels of $\mathrm{AgNO}_{3}$ excluding o.3o per cent. $\mathrm{AgNO}_{3}$, emergence decreased with increasing $\mathrm{AgNO}_{3}$

TABLE 2

$\mathrm{AgNO}_{3}$ and P.T.C. mixed in the medium

Number of adult flies emerging from roo larve for various concentrations of $\mathrm{AgNO}_{3}$ and P.T.C.

\begin{tabular}{|c|c|c|c|c|c|c|c|c|}
\hline \multirow{2}{*}{$\begin{array}{c}\text { Per cent. } \\
\mathrm{AgNO}_{3}+ \\
\text { per cent. } \\
\text { P.T.C. }\end{array}$} & \multicolumn{4}{|c|}{ Mass bred } & \multicolumn{4}{|c|}{ Inbred } \\
\hline & ++ & $e^{11}+$ & $e^{11} e^{11}$ & Total & ++ & $e^{11}+$ & $e^{11} e^{11}$ & Total \\
\hline $0.15+0.03$ & 89 & 86 & $8_{5}$ & 260 & 88 & 89 & 88 & 265 \\
\hline $0.15+0.09$ & 109 & 8 & I & II 8 & I & $\cdots$ & 27 & 28 \\
\hline $0.15+0.12$ & 45 & I I & 4 & 60 & & & & \\
\hline $0.20+0.02$ & $5^{6}$ & 70 & I5 & $14 \mathrm{I}$ & 90 & $5^{8}$ & 73 & 221 \\
\hline $0.20+0.03$ & 3 & 4 & I $*$ & 8 & 2 & 23 & 9 & 34 \\
\hline $0.20+0.04$ & & & & & $\cdots$ & & 2 & 2 \\
\hline $\begin{array}{l}0 \cdot 20+0 \cdot 06 \\
0 \cdot 20+0 \cdot 09\end{array}$ & $\cdots$ & I & $\cdots$ & I & $\cdots$ & I & 3 & 4 \\
\hline $0.20+0.09$ & $\cdots$ & ‥ & $\cdots$ & $\cdots$ & $\dddot{48}$ & I & $\cdots$ & $\begin{array}{r}I \\
89\end{array}$ \\
\hline $\begin{array}{l}0.25+0.02 \\
0.25+0.03\end{array}$ & $\begin{array}{r}35 \\
4\end{array}$ & 37 & $\begin{array}{l}22 \\
\ldots\end{array}$ & 94 & $\begin{array}{l}4^{8} \\
\ldots\end{array}$ & $\begin{array}{c}b \\
\ldots\end{array}$ & $\begin{array}{r}35 \\
2\end{array}$ & $\begin{array}{r}89 \\
2\end{array}$ \\
\hline $\begin{array}{l}0.25+0.03 \\
0.25+0.06\end{array}$ & $\ldots$ & $\begin{array}{l}3 \\
\ldots\end{array}$ & $\begin{array}{l}\cdots \\
\cdots\end{array}$ & $\begin{array}{l}7 \\
\ldots\end{array}$ & $\cdots$ & $\cdots$ & 4 & $\ldots$ \\
\hline $0.25+0.09$ & $\ldots$ & $\dddot{c o}$ & I & I & 5 & $0^{2}$ & 6 & 13 \\
\hline $0.30+0.03+$ & I0O & 68 & 944 & 262 & 100 & 87 & 96 & 283 \\
\hline $0.30+0.09+$ & IO4 & 27 & IIOT & 247 & 94 & $5^{I}$ & $92 \uparrow$ & 237 \\
\hline
\end{tabular}

* $\mathrm{F}_{2} \mathrm{~s}$ emerged here so the data are not reported.

$\dagger \mathrm{F}_{2}$ s emerged here, but the deficiency of $e^{11}+$ genotypes is so great the data are valid.

\pm These cultures were set up after the rest, using another batch of medium. This may account for the large numbers of flies which emerged.

concentration. Similarly at all levels of $\mathrm{AgNO}_{3}$, emergence decreased with increasing P.T.C. concentration.

We commenced with the hypothesis that the heterozygote would be favoured when P.T.C. and $\mathrm{AgNO}_{3}$ were mixed in the medium. However, in several cases there was negative heterosis. At 0.30 per cent. $\mathrm{AgNO}_{3}$, this occurred for both the mass bred and inbred flies. Similarly, there is negative heterosis of the inbred flies for 0.20 and 0.25 per cent. $\mathrm{AgNO}_{3}$ mixed with 0.02 per cent. P.T.C. Two concentrations gave slight but insignificant positive heterosis, namely: the mass bred flies at 0.20 per cent. $\mathrm{AgNO}_{3}$ and 0.02 per cent. P.T.C., and the inbred flies at 0.20 per cent. $\mathrm{AgNO}_{3}$ and 0.03 per cent. P.T.C. More data are needed to prove whether both positive and negative heterosis are possible. The occurrence of negative heterosis indicates that the two inhibitors can be complementary in their action on the heterozygote so that its viability is depressed most. 


\section{RESULTS WITH A DIFFERENT e ALLELE}

Results were collected for $\mathrm{AgNO}_{3}$ and P.T.C. on an oatmeal treacle medium in the Department of Genetics, University of Cambridge, using an Oregon stock obtained from the Department of Genetics, University of Birmingham, and a different ebony allele $(e)$ from the one studied previously. In table 3 percentage emergence after correcting for the control is given. The total emergence of a genotype for each treatment was divided by its emergence on the control medium and multiplied by roo. Correction for the control was necessary on the Cambridge medium as $e e$ and $e^{11} e^{11}$ emergence on the control medium was often worse than that of the wild type or heterozygous genotypes.

TABLE 3

Number of adult fies emerging from roo larve for various concentrations of $\mathrm{AgNO}_{3}$ and P.T.C. using Cambridge and Davis stocks. (The data were collected in Cambridge.)

\begin{tabular}{|c|c|c|c|c|c|c|}
\hline & \multicolumn{3}{|c|}{ Cambridge } & \multicolumn{3}{|c|}{ Davis } \\
\hline & ++ & $e+$ & $e e$ & ++ & $e^{11}+$ & $e^{11} e^{11}$ \\
\hline Control . & 100 & IOO & 100 & 100 & 100 & 100 \\
\hline 0.03 per cent. P.T.C. & 100 & 97 & 60 & 59 & 72 & 62 \\
\hline 0.05 per cent. P.T.C. & 100 & 95 & 26 & 57 & 53 & 3 \\
\hline 0.12 per cent. P.T.C. & 74 & 73 & 0 & 29 & 25 & 0 \\
\hline $\begin{array}{l}0.35 \text { per cent. } \mathrm{AgNO}_{3} \\
0.40 \text { per cent. } \mathrm{AgNO}_{3}\end{array}$ & $\begin{array}{l}78 \\
34\end{array}$ & $\begin{array}{l}74 \\
52\end{array}$ & $\begin{array}{l}75 \\
60\end{array}$ & $\begin{array}{l}92 \\
78\end{array}$ & $\begin{array}{l}99 \\
85\end{array}$ & $\begin{array}{l}76 \\
98\end{array}$ \\
\hline
\end{tabular}

P.T.C. affected the Davis stocks rather more severely than the Cambridge stocks, and the converse was true for $\mathrm{AgNO}_{3}$. The P.T.C. effect was clear, for both $e e$ and $e^{11} e^{11}$ stocks were inhibited by P.T.C. at much lower concentrations than the wild type and heterozygous genotypes. The $\mathrm{AgNO}_{3}$ effect was less obvious than the P.T.C. effect. On 0.40 per cent. $\mathrm{AgNO}_{3}$ both ebony genotypes were at a slight advantage and, on 0.35 per cent. $\mathrm{AgNO}_{3}, e^{11} e^{11}$ was at a slight disadvantage. Generally, in other tests, ebony genotypes have shown a slightly higher emergence than ++ , but the difference has not been as marked as in the results presented in table I. A food batch effect may account for the relative uncertainty of the $\mathrm{AgNO}_{3}$ effect on the Cambridge food. For example, on the Cambridge food, but not the Davis food, flies emerged on $0 \cdot 40$ per cent. $\mathrm{AgNO}_{3}$.

It is not surprising that there is a difference between the stocks since in section 4 the existence of modifiers of melanin production and hence of tolerance to the inhibitors, was demonstrated. It is, however, reassuring that the stocks inhibited most on P.T.C. did best on $\mathrm{AgNO}_{3}$, which is the result obtained when selecting darker heterozygotes. In view of this agreement, it seems that we are dealing with minor differences in melanin production between the stocks. 


\section{COMPETITION EXPERIMENTS}

\section{(i) Method}

Experiments were done at two levels of competition with the $e$ allele using 0.25 per cent. $\mathrm{AgNO}_{3}$ or 0.04 per cent. P.T.C. in the medium together with controls in normal medium. The two levels of competition were 25 and Ioo larvæ per vial with about $8 \mathrm{gm}$. of medium. Eight replicates of 25 larvæ and 2 replicates of 100 larvæ were made up, making a total of 200 larvæ per treatment. On emergence, the flies were counted daily to obtain frequency distributions of emergence.

\section{(ii) Results}

In table 4 the total number of flies that emerged from 200 larvæ is given with the mean and variance of the number of days taken to emerge.

On P.T.C., as expected, ee emergence was inhibited most. However significantly fewer ee flies emerged at the low level of competition (25 larvæ per replicate) than the high level ( Ioo larvæ per replicate). Perhaps at the high level, ee flies tend to detoxify the medium, allowing more flies to survive. The different levels of competition did not affect ++ and $+e$ flies significantly.

On $\mathrm{AgNO}_{3}$, at the low level, more ++ flies than ee emerged. This is contrary to the results presented so far, but when the larvæ that pupated but did not emerge were taken into account, the number of ++ and $e e$ flies emerging was about equal, which agrees reasonably with other data on the Cambridge food. At the high level, fewer flies of all genotypes emerged, probably because of competition. There was little difference between genotypes in the number of flies emerging.

On the control medium, the high level retarded emergence by about $\frac{1}{2}$ day, on 0.04 per cent. P.T.C. by about I day except for the ee genotype, and on 0.25 per cent. $\mathrm{AgNO}_{3}$ emergence was retarded by 2 to 4 days, all the differences between the two levels of competition being significant except on $0 \cdot 04$ per cent. P.T.C.

At the low level on $\mathrm{AgNO}_{3}$, ee flies emerged a day later than ++ and $+e$, but at the high level this was reversed, so that ++ flies took longer to emerge than $e e$. If time taken to emerge is a component of fitness, which is likely, ee flies at the high level of competition on $\mathrm{AgNO}_{3}$ are in some respects fitter than ++ flies. This emphasises the difficulty of using the ability of Ioo larvæ to emerge as adults as the sole criterion of fitness, as the fitness of a population is made up of many more components than this.

Few conclusions can be drawn from the variances of emergence time in the controls, since flies were counted at daily intervals, and in most cases all emerged in a period of $I$ to 2 days. The variances for the flies grown on treated food are more informative. In all cases 


\section{TABLE 4}

Means and variances of emergence time at two levels of competition

(a) Means and variances, with total numbers of flies which emerged from a total of 200 larvæ (8 replicates of 25 larvæ, and 2 replicates of 100 )

\begin{tabular}{|c|c|c|c|c|c|c|c|}
\hline \multirow{3}{*}{\multicolumn{2}{|c|}{ Genotype }} & \multicolumn{2}{|c|}{ Control } & \multicolumn{2}{|c|}{ 0.04 per cent. P.T.C. } & \multicolumn{2}{|c|}{$0 \cdot 25$ per cent. $\mathrm{AgNO}_{3}$} \\
\hline & & \multicolumn{6}{|c|}{ Larvæ per replicate } \\
\hline & & 25 & 100 & 25 & 100 & 25 & 100 \\
\hline++ & $\begin{array}{l}\text { total } \\
\text { mean } \\
\text { variance }\end{array}$ & $\begin{array}{l}185 \\
7.46 \\
0 \cdot 07\end{array}$ & $\begin{array}{l}185 \\
7.89 \\
0.26\end{array}$ & $\begin{array}{l}155 \\
7 \cdot 75 \\
0 \cdot 26\end{array}$ & $\begin{array}{l}178 \\
8.93 \\
0.63\end{array}$ & $\begin{array}{c}163(3)^{*} \\
8 \cdot 05 \\
0 \cdot 52\end{array}$ & $\begin{array}{c}60(38) \\
12 \cdot 07 \\
3 \cdot 30\end{array}$ \\
\hline et & $\begin{array}{l}\text { total } \\
\text { mean } \\
\text { variance }\end{array}$ & $\begin{array}{l}182 \\
7 \cdot 00 \\
0 \cdot 32\end{array}$ & $\begin{array}{l}185 \\
7.51 \\
0.02\end{array}$ & $\begin{array}{l}168 \\
7 \cdot 9^{2} \\
0 \cdot 44\end{array}$ & $\begin{array}{l}\mathrm{I} 46 \\
8 \cdot 7 \mathrm{I} \\
\mathrm{O} \cdot 94\end{array}$ & $\begin{array}{c}\text { I } 39(\mathrm{ro}) \\
8 \cdot 86 \\
2 \cdot \mathrm{I} 7\end{array}$ & $\begin{array}{c}76(34) \\
\text { II } 67 \\
4 \cdot 01\end{array}$ \\
\hline$e e$ & $\begin{array}{l}\text { total } \\
\text { mean } \\
\text { variance }\end{array}$ & $\begin{array}{l}184 \\
7 \cdot 29 \\
0 \cdot 32\end{array}$ & $\begin{array}{l}\text { I } 78 \\
7 \cdot 73 \\
\text { o. } 33\end{array}$ & $\begin{array}{c}\text { I } 7 \\
\text { 10.56 } \\
\text { o.93 }\end{array}$ & $\begin{array}{c}47 \\
10 \cdot 65 \\
1 \cdot 56\end{array}$ & $\begin{array}{c}93(72) \\
9 \cdot 28 \\
2 \cdot 67\end{array}$ & $\begin{array}{c}60(4 \mathrm{I}) \\
11 \cdot 27 \\
2 \cdot 52\end{array}$ \\
\hline
\end{tabular}

* In brackets are the numbers of pupæ which did not emerge.

(b) Variance ratios for high level/low level

\begin{tabular}{|c|c|c|c|}
\hline & Control & 0.04 per cent. P.T.C. & 0.25 per cent. $\mathrm{AgNO}_{3}$ \\
\cline { 2 - 3 }++ & $3.5 \mathrm{I}$ & 2.39 & 6.34 \\
$e+$ & 2.15 & $\mathrm{I} \cdot 84$ \\
$e e$ & $\mathrm{I} .05$ & $\mathrm{I} \cdot 68$ & 0.94 \\
\hline
\end{tabular}

(c) Data rearranged as $2 \times 2$ tables to test for genotype $\times$ environmental interactions

\begin{tabular}{|c|c|c|c|c|c|c|}
\hline & \multicolumn{2}{|c|}{ Control } & \multicolumn{2}{|c|}{ 0.04 per cent. P.T.C. } & \multicolumn{2}{|c|}{0.25 per cent. $\mathrm{AgNO}_{3}$} \\
\hline & 25 & 100 & 25 & 100 & 25 & 100 \\
\hline$+e_{e e}^{+}$ & $\begin{array}{l}185 \\
184\end{array}$ & $\begin{array}{l}185 \\
178\end{array}$ & $\begin{array}{r}155 \\
17\end{array}$ & $\begin{array}{r}\times 78 \\
47\end{array}$ & $\begin{array}{r}63 \\
93\end{array}$ & $\begin{array}{l}6 o \\
6 o\end{array}$ \\
\hline $\begin{array}{c}\chi_{1}^{2} \text { on } \\
2 \times 2 \text { table }\end{array}$ & \multicolumn{2}{|c|}{$\begin{array}{c}0.02 \\
0.8<\mathrm{P}<0.9\end{array}$} & \multicolumn{2}{|c|}{$\begin{array}{c}7.94 \\
\mathrm{P}<0.01\end{array}$} & \multicolumn{2}{|c|}{$\begin{array}{c}5.77 \\
\mathrm{P}<0.022\end{array}$} \\
\hline
\end{tabular}


except ee on $\mathrm{AgNO}_{3}$, the higher level of competition spread the distribution of emergence, so increasing the variances. The increase was greatest for ++ and least for ee flies (table $4 b$ ). On $\mathrm{AgNO}_{3}$ at the high level, the variance was least for $e e$ and greatest for $e+$ and ++ , which agrees with an earlier unpublished analysis with the $e^{11}$ allele. On P.T.C., at the high level, the variance was greatest for $e e$ and least for ++ which is the reverse of the order of magnitude on $\mathrm{AgNO}_{3}$. Thus, at this level of competition, the genotype, which, on the basis of most observations, is most severely affected by a treatment, exhibited the greatest variability in emergence time. This is reasonable, since it may be supposed that a large variance would be a manifestation of the severe stress to which a genotype is subjected.

At the low level of competition the variances are probably less meaningful, as there was sufficient food to make competition negligible. On P.T.C., ++ gave the smallest and $e e$ the largest variance as was so at the high level. On $\mathrm{AgNO}_{3}$, no correspondence between the two levels occurred, since at the low level, ee showed the greatest variance and ++ the least. At the low level, however, ee showed poorest emergence, which agrees with a conclusion drawn from the high level on P.T.C., where it was noted that the variances increased as emergence decreased. Once again, therefore, the genotype most severely affected by a treatment gave the greatest variance. Taking into account pupal mortality, emergence of all genotypes was almost equivalent at the low level. Even so, the large number of ee pupæ which did not emerge, demonstrates the severe environmental stress involved.

Between the low and high levels on $\mathrm{AgNO}_{3}$ there was a significant genotype $\times$ environmental interaction. Rearranging the data as in table $4^{c}$ demonstrates this. $\chi^{2}{ }_{1}$ values on the $2 \times 2$ tables formed by the two levels of competition and the two genotypes ee and ++ are given. For $\mathrm{AgNO}_{3}, \chi^{2}{ }_{1}=5.77(\mathrm{P}<0 \cdot 02)$. The significance of this $\chi^{2}{ }_{1}$ is due to the relatively poor emergence of $e e$ flies at the low level. On P.T.C., the interaction is more striking $\left(\chi^{2}{ }_{1}=7 \cdot 94, \mathrm{P}<0 \cdot 0 \mathrm{I}\right)$. As discussed already the emergence of $e e$ flies was greater at the high level than at the low level. In general, it may be expected that genotype $\times$ environmental interactions will be greatest when an organism is under severe stress, as the genotypes will be very sensitive to small changes in environment, such as the change in the level of competition from 25 to roo larvæ per replicate.

One further competition experiment was done on 0.04 per cent. P.T.C. Genotypes ++ and $e e$ were mixed in various proportions, all,$++ 75++: 25 e e, 50++: 50 e e, 25++: 75 e e$, and all ee. Four replicates of roo larvæ were counted for each proportion on treated and untreated food, and emergence as adults recorded (table 5).

On 0.04 per cent. P.T.G., ee flies emerged only from cultures consisting of all ee larvæ and from $25++: 75 e e$. At higher concentrations of ++ larvæ, no ee flies emerged, showing that the level of competition had increased so as to prevent any ee flies emerging. 
Thus $e e$ emergence is dependent on the proportion of the co-existing ++ genotypes. Emergence of ++ flies was high on 0.04 per cent. P.T.C., although somewhat lower than the control, but no significant

TABLE 5

Emergence on 0.04 per cent. P.T.C. for 4 oo larve (4 replicates of roo) of ++ and ee genotypes mixed in different proportions

\begin{tabular}{|c|c|c|c|c|c|c|c|c|}
\hline & \multicolumn{8}{|c|}{ Proportion of $++: e e$} \\
\hline & \multirow{2}{*}{$\begin{array}{l}\text { all } \\
++\end{array}$} & \multicolumn{2}{|c|}{$75++: 25 e e$} & \multicolumn{2}{|c|}{$50++: 50 e e$} & \multicolumn{2}{|c|}{$25++: 75 e e$} & \multirow{2}{*}{$\begin{array}{c}\text { all } \\
e e\end{array}$} \\
\hline & & ++ & $e e$ & ++ & $e e$ & ++ & $e e$ & \\
\hline Control & $37^{8}$ & 278 & $8_{2}$ & 201 & 162 & 95 & 285 & 352 \\
\hline $\begin{array}{l}\text { 0.04 per cent. } \\
\text { P.T.C. }\end{array}$ & 327 & 266 & $\ldots$ & 168 & $\cdots$ & 89 & 2 & 7 \\
\hline
\end{tabular}

difference between the levels of competition occurred. The ee flies from $25++: 75$ ee emerged about 3 days after the ++ flies had all emerged.

\section{DISCUSSION}

The results given in this paper deal with biochemical stresses applied by feeding ebony and wild type larvæ with the two inhibitors $\mathrm{AgNO}_{3}$ and P.T.C. On 0.04 per cent. P.T.C. using the Davis food recipe, $e^{11} e^{11}$ larvæ did not emerge, whereas on 0.12 per cent. P.T.C. a few ++ and $e^{11}+$ larvæ emerged. Wolsky and Kalicki (r959) have shown that ebony larvæ have about one-half the tyrosinase content of wild type larvæ. As P.T.C. is a tyrosinase inhibitor, it seems reasonable that it should be more lethal to ebony than wild type flies. There was no such striking difference between the effects of $\mathrm{AgNO}_{3}$ on the three genotypes, although ebony flies generally survived better on $\mathrm{AgNO}_{3}$ than the wild type. If it is assumed that melanin pigment counteracts the lethal effect of $\mathrm{Ag}$ ions, i.e. acts as a detoxification agent, then the more melanin that is produced, the greater the concentration of $\mathrm{AgNO}_{3}$ that can be tolerated.

The lines in which dark $e^{11}+$ flies were selected show that the relevant factor is melanin synthesis. As expected, the flies produced by selection were more resistant to $\mathrm{AgNO}_{3}$ and less resistant to P.T.C. than before selection. Presumably, selection has acted on a background of modifiers affecting melanin synthesis. The difference between the reaction of $e^{11} e^{11}$ and ++ stocks to both inhibitors became negligible after selection, so that dominance and recessivity in relation to tolerance to the inhibitors were changed by the selection of appropriate modifiers. Furthermore, the Cambridge and Davis wild 
type and ebony stocks differed slightly in their ability to tolerate the inhibitors, presumably because these stocks differ in the modifiers they possess.

That it is possible to find modifiers that affect a specific biochemical pathway is of considerable interest, since it offers a better hope of finding out their exact action than is likely for modifiers of the quantitative traits more commonly used in Drosophila, such as fertility, wing length, etc. There is the possibility that the exact biochemical action of the modifiers may be determinable. We may suppose that they alter enzyme production, or utilisation, or increase or decrease the concentration of a substrate, or they may have some other function. Nolte (I959) demonstrated the existence of modifiers in the determination of red and brown eye pigments in Drosophila. This may be another relatively simple biochemical pathway amenable to a more exact analysis.

The negative heterosis observed when the two inhibitors were mixed in the medium might be of evolutionary interest. By a suitable adjustment of the medium, both $e^{11} e^{11}$ and ++ could co-exist but would be virtually unable to exchange genes or share the same gene pool. Conditions are therefore created in which the $e^{11} e^{11}$ and ++ genotypes might diverge, either by the development of a polymorphic system, or by the production of an isolation barrier.

Exposing a population of flies segregating at the ebony locus to a heterogeneous environment consisting of food with P.T.C. and $\mathrm{AgNO}_{3}$ separately would provide a system of disruptive selection. Mather (1955) regards disruptive selection within a population resulting from heterogeneous environmental conditions as contributing to genetic diversity in outbreeding species, and suggests that the outcome may be a polymorphism. Thoday (1958) and Thoday and Boam (I959) presented evidence in Drosophila melanogaster where disruptive selection, without isolation, lead to a polymorphism for sterno-pleural chæta-number. Mather (1955) argues that under some circumstances it might be possible to go from a polymorphism to genetic isolation of the groups and hence speciation. In the situation under discussion, this may be expecting too much. However, as well as the major gene ebony, modifiers of melanin formations have been demonstrated which would be essential for disruptive selection to be effective.

Section 7 deals with competition experiments on critical concentrations of the two inhibitors. Increasing the level of competition from 25 to Ioo larvæ per vial increased the time taken to emerge as adults and the variance of this time. On untreated food, roo larvæ per vial is not a high level of competition so that there was almost no effect. On the food with critical concentrations of inhibitor, the situation was radically altered, for the minor change in competition had major effects on the number of flies emerging and the time they took to emerge, both of which are, in some way, components of fitness. 
Considering total emergence, a large genotype $\times$ environmental interaction wasfound between the two levels of competition on the inhibitors. This shows clearly the variability of this component of fitness under conditions of severe stress. Fitness in most of the experiments discussed has been measured as the number of adults emerging from a given number of larvæ, but this is not necessarily a true measure of fitness under natural selection, by which we mean the ability of a species to survive and reproduce over a long period of time (Thoday, I953). In the present study, no account has been taken of the viability and fertility of the adults and their mating ability. At the high level of competition on $\mathrm{AgNO}_{3}$, emergence was almost equivalent for all genotypes, but because the $e e$ flies emerged somewhat more rapidly than the ++ flies, they could, using the speed of emergence as a criterion of fitness, be regarded as fitter than the ++ flies. If total emergence were the sole criterion of fitness, then the genotypes could be regarded as equally fit. At these critical levels of the inhibitors, the importance of various components of fitness becomes apparent. For example, in a situation in which food was abundant, then total emergence would probably be of more importance to the species than in a situation in which the food supply was so critical as to eliminate weaker types and generally retard the rate of development. In this latter situation, the rate of emergence would assume much more importance. Under conditions of severe stress, it seems that correlations between the various components of fitness will be lower than under conditions of low stress. To judge a genotype as fitter than another on the basis of one criterion is rather dangerous, for other criteria may not necessarily be closely correlated.

In a natural population, the fitness of a genotype usually depends on the nature and proportion of the co-existing genotypes (Lewontin, 1955; Parsons, 1959). The experiments with P.T.G., in which ++ and $e e$ were mixed in varying proportions, were an attempt to collect data on this aspect of fitness. Ebony flies only emerged when competition from ++ was low, showing a difference in the fitness of $e e$ according to the proportion of co-existing genotypes. On the control medium, no such variability was detectable for either genotype, and on 0.04 per cent. P.T.C., the ++ flies which were hardly affected by the inhibitor showed no significant variation. The ee genotypes which are under a severe stress therefore show variability according to the proportion of competing genotypes.

These experiments therefore demonstrate quite forcibly some of the variables which may affect fitness, and emphasise that the fitness of a genotype is made up of all the components leading to its survival and its capacity to reproduce over a long period of time. Furthermore, studying organisms under a severe stress enables us to make inferences on fitness, for minor changes in environment, such as a slight alteration in competition, or the proportion of co-existing genotypes, can have a major effect on some, but not necessarily all 
the components of fitness. In a population not under stress, such as the controls in the experiments discussed, minor variations have no appreciable effect.

\section{SUMMARY}

I. The emergence ability of ebony, wild type and heterozygous ebony newly hatched larvæ on two melanin inhibitors, silver nitrate $\left(\mathrm{AgNO}_{3}\right)$ and phenyl-thio-carbamide (P.T.C.) has been studied. P.T.C. was more lethal to ebony and $\mathrm{AgNO}_{3}$ to wild type. A mixture of the two inhibitors occasionally gave severe negative heterosis suggesting the possibility of the creation of a polymorphism.

2. Modifiers affecting melanin production were demonstrated. After selection for increased melanisation, the emergence of the flies on the inhibitors was compatible with the hypothesis that modifiers had caused quantitative variations in the biochemical synthesis of melanin. Differences between two wild type stocks and two ebony stocks were suggested to be due to modifiers.

3. The distribution of emergence time was studied for two levels of competition ( 25 and Ioo larvæ per replicate respectively). Between levels of competition, significant genotype $\times$ environmental interactions were found. The mean emergence time on the two inhibitors was longer than on the controls, and at the high level of competition longer than at the low level. Similarly, the variances of emergence time were greatest at the high level. Genotypes under the severe stress caused by the inhibitors therefore usually exhibited a large variance in emergence time, and often substantial genotype $\times$ environmental interactions. Furthermore, it was shown that the proportion and nature of the co-existing genotypes affect emergence at these critical levels of stress. The implications of some of these findings, and their bearing on the concept of fitness are discussed.

\section{REFERENCES}

HOLT, s. B. I948. The effect of maternal age on the manifestation of a polydactyl gene in mice. Ann. Eug., I4, I44-1 47.

KROMAN, R. A., AND PARSONS, P. A. 1960. The genetic basis of two melanin inhibitors in Drosophila melanogaster. Nature, $186,4 \mathrm{I}$ I-412.

LERNER, A. B., AND FITZPATRICK, T. B. I950. Biochemistry of melanin formation. Physiol. Rev., 3o, 91-126.

LEWONTIN, R. G. I955. The effects of population density and competition on viability in Drosophila melanogaster. Evolution, 9, 27-41.

MATHER, K. I955. Polymorphism as an outcome of disruptive selection. Evolution, 9, 52-6r.

NOLTE, D. J. I959. Polygenes in eye pigment production in Drosophila species. Evolution, $13, \mathrm{I}-8$.

PARSONS, P. A. I 959 . Dependence of genotypic viabilities on co-existing genotypes in Drosophila. Heredity, $13,393-402$.

RAPOPORT, J.A. I947. On the synthesis of gene-products in equimolecular quantities. Amer. Nat., 81, 30-37. 
thoday, J. м. 1953. Components of fitness. Symposia Soc. Exptl. Biol., 7, 96-i I 3. THODAY, J. M. 1958. Effects of disruptive selection: the experimental production of a polymorphic population. Nature, I8I, I I 24-I I 25.

thodAy, J. M., AND воAм, т. в. 1959. Effects of disruptive selection. II. Polymorphisms and divergence without isolation. Heredity, 13, 205-218.

WOLSKY, A., AND KALICKI, H. G. I959. Oxidative metabolism and puparium formation in the ebony mutant of Drosophila melanogaster. Nature, I83, I I 29. 